\title{
Estados y desarrollo democrático en el pensamiento de 0'Donnell*
}

States and democratic development in O'Donnell's thinking

\section{Walid Tijerina Sepúlveda**}

\begin{abstract}
RESUMEN
Desde mediados del siglo pasado, Guillermo O'Donnell se consolidó como uno de los primeros politólogos en identificar de manera sistémica las caracteristicas de los Estados latinoamericanos autoritarios, lo que llamó el Estado burocrático-autoritario. Con ello, contribuyó al comienzo de la desmitificación de los Estados autoritarios en América Latina. Estas aportaciones de O'Donnell fueron asimiladas gradualmente por la literatura en torno al desarrollo democrático de América Latina. Con ello, al mismo tiempo, se crearon nuevas conceptualizaciones y líneas de investigación. El objetivo del presente artículo es hacer un recuento de la trayectoria de la obra politica de O'Donnell sobre América Latina para vincularla con las últimas tendencias en la materia y resaltar cómo pudiera fungir de guía para los nuevos retos de gobernanza en la región.
\end{abstract}

\section{PALABRAS CLAVE}

Desarrollo, democracia, América Latina, gobernanza multinivel.

\begin{abstract}
Since the middle of the last century, Guillermo O'Donnell was consolidated as one of the first political scientists to systematically identify the characteristics of the authoritarian Latin American States, what he called the bureaucratic-authoritarian State. With this, he contributed to the beginning of the demystification of authoritarian states in Latin America. These contributions by O'Donnell were gradually assimilated by the literature on the democratic development of Latin America. At the same time, new conceptualizations and lines of research were created. The objective of this article is to give an account of the trajectory of O'Donnell's political work on Latin America to link it with the latest trends in the field and highlight how it could serve as a guide for new governance challenges in the region.
\end{abstract}

\section{KEYWORDS}

Development, democracy, Latin America, multilevel governance.

*Artículo recibido el 6 de agosto de 2017 y aceptado para su publicación el 17 de noviembre de 2017

** Profesor-investigador en la Universidad Autónoma de Nuevo León (walid.tijerina@gmail.com) ORCID: 0000-00020856-7103 
SUMARIO

1. Introducción

2. El Estado latinoamericano y el reto de la centralización

3. La crisis de Estado en América Latina a finales del siglo xx: de democracias en transición a democracias en delegación

4. Gobernanza multinivel y poder infraestructural: ¿remedio para el esquizofrénico Estado latinoamericano?

5. Entre agencias (democráticas) y estructuras (no democráticas): incrementando la intensidad de las ciudadanías

6. Conclusión

\section{INTRODUCCIÓN}

Lo que se convertiría en América fue descubierto en terrenos inciertos. Como lo relató 0'Gorman, la idea de América fue más una cuestión de interpretación e invención que un descubrimiento. ${ }^{1}$ La "invención de América" se fundó en falsas premisas: nuestro continente estaba lejos de ser esa isla cercana a Japón que Cristóbal Colón afirmó haber encontrado. América ha cambiado, pero sigue siendo, desde entonces, algo elusivo y polisémico. Un territorio, una herencia colonial, un conjunto de Estados, pueblos y naciones. Comparte entonces esa calidad escurridiza con la idea de gobierno que, tras siglos de vaivenes, echó raíces sobre ella: la democracia.

La democracia tardaría en germinar de manera generalizada en América Latina, pero ahora es el panorama habitual de nuestros países. El problema actualmente es que la democracia se ha convertido en algo igual de elusivo que aquella América inventada. Parece ser que fue hasta los inicios de este siglo que descubrimos que a la democracia había que hacerla nuestra, más allá de meros trasplantes o recetas. Esa cualidad elusiva de la democracia ha resultado en descontentos generalizados. Porque tenemos elecciones y un voto universal, pero el asedio de la pobreza, la desigualdad y las crisis de representación siguen presentes. Es decir, tenemos democracias electorales a lo largo y ancho de América Latina, pero estamos lejos de llegar a una democracia ciudadana. Tal vez, más allá de agendas, lo que nuestra democracia necesita es también una cartografía para su progreso.

En este orden de ideas, la obra de Guillermo O'Donnell ha sido elemental para "mapear" los variados territorios que nuestro continente presenta

\footnotetext{
${ }^{1}$ O'Gorman, Edmundo, La invención de América, México, Fondo de Cultura Económica, 1958.
} 
en aspectos democráticos. ${ }^{2}$ Lo anterior se da bajo el entendido de que la democracia en América Latina sigue siendo, como la definió Waldo Ansaldi, un "barco a la deriva". ${ }^{3}$ Incluso en la coyuntura mundial actual, más allá de regionalismos, la democracia en general parece haberse convertido en un barco a la deriva. Lo anterior se refleja en controversiales referéndums como el Brexit, Grexit, Cataluña o en elecciones contagiadas de rencores como en la de Estados Unidos.

El rencor ciudadano, no obstante, tiene una causante: las sempiternas falencias de meras democracias electorales. Estas deficiencias de las democracias, o lo que O’Donnell llamó "ciudadanías de baja intensidad", han impactado de manera contundente en la legitimidad de los Estados democráticos. Ahora bien, ¿cómo es que el Estado, ya sea en Europa o en América Latina, perdió tal nivel de legitimidad?

En el caso de América Latina, la transición de democracias electorales a democracias ciudadanas parece ser un requerimiento evolutivo para que nuestros países superen las crisis actuales de legitimidad. En específico, la obra de O'Donnell pudiera muy bien representar el soporte teórico de dicha transición, pues enmarca, desde hace décadas, los retos de gobernanza democrática y multinivel que los Estados están enfrentando actualmente. Hoy más que nunca se hace evidente que las meras "poliarquías" o democracias electorales no son suficientes como respaldo institucional para el desarrollo democrático de los países. El objetivo del presente artículo es, por tanto, resaltar o mapear la evolución de ideas de O'Donnell en torno al desarrollo de los Estados latinoamericanos para buscar reconstruir ese puente que ahora hace falta entre nuestras democracias electorales y los nuevos retos que la gobernanza exige en la región.

El esquema de este artículo es el siguiente. En la próxima sección se hará referencia a las conceptualizaciones de los Estados burocrático-autoritarios de América Latina, para considerar en la sección posterior los retos y obstáculos que las transiciones democráticas tuvieron en la región, los cuales se reflejan primeramente en las llamadas "democracias delegativas". Las siguientes secciones relacionan las propuestas de 0’Donnell en busca de una remediación de las desiguales capacidades del Estado latinoamericano, ya sea por cuestiones regionales o sociales. Es en este último punto donde se revisarán las últimas contribuciones del autor y se hará hincapié en el curioso patrón de desarrollo

\footnotetext{
2 O'Donnell, Guillermo, "Estado, democratización y ciudadanía", Revista Nueva Sociedad, núm. 128.

${ }^{3}$ AnSAldI, Waldo, La democracia en América Latina: ¿un barco a la deriva?, México, Fondo de Cultura Económica, 2007.
} 
que los derechos han tenido en la región y en la recaracterización de ciudadanos como agentes prioritarios en las democracias latinoamericanas.

\section{El Estado latinOAmERicano y El RETO DE la CENTRALIZACión}

¿Cuáles son los factores determinantes para la supervivencia del Estado moderno? ¿Cuáles son las herramientas o estrategias que algunos Estados aplicaron para prevalecer sobre otros? Esta es, de fondo, una de las preguntas que la obra de O'Donnell ha analizado para el caso de los Estados latinoamericanos en comparación o perspectiva con Estados europeos. ${ }^{4}$ Uno de los grandes retos de dichos Estados ha sido implementar instituciones políticas cultivadas en terrenos extranjeros.

En la ya clásica obra de Charles Tilly y Gabriel Ardant respecto a la consolidación de los Estados europeos en el transcurso de los siglos XVI y XVII, la autonomía de los Estados se vincula con otra de las características esenciales para su consolidación: la centralización. ${ }^{5}$ La consolidación estable y progresiva de un Estado exigía llevar a cabo una centralización de sus funciones, en oposición a los frágiles Estados-ciudad que retrató Maquiavelo o los "Estados combatientes" previos a las primeras grandes dinastías chinas. La creciente centralización de los roles del Gobierno favorecía, a su vez, las capacidades de recaudación del Estado.

Además, la captación potencializada de recursos tributarios contribuía después a los esfuerzos estaduales de consolidar ejércitos permanentes y aplicar su ley con un uso de la fuerza más efectivo, lejos de la fragilidad y el frecuente desorden del feudalismo. Desde el siglo XVI, por tanto, la unidad y centralización de Estados europeos se convirtió en un aspecto fundamental para consolidar la seguridad del propio Estado y de sus habitantes tanto hacia el interior como al exterior. Eventualmente, la creciente sofisticación militar de los Estados fue exigiendo mayores recursos económicos, por lo que las capacidades de centralización se tornaron en una especie de eje rector.

¿Pero cómo cristalizar las mismas capacidades de centralización en medio de las fragmentadas y conflictivas sociedades de América Latina? Como lo retrataron Wiarda \& Kline, el retiro súbito de las monarquías españolas y portuguesas durante el siglo xIX agudizaron las "tendencias centrífugas" del poder, ocasionando que el poder político se difundiera entre caciques y jefes

\footnotetext{
${ }^{4}$ O'Donnell, Guillermo, Polyarchies and the (Un)Rule of Law in Latin America, Estados Unidos, LASA, 1998.

${ }^{5}$ Tilly, Charles y Ardant, Gabriel, The Formation of National States in Western Europe, Estados Unidos, Princeton University Press, 1975. Véase también el concepto de "poder central" de Michael Mann en The Sources of Social Power.
} 
locales que buscaban llegar al palacio nacional. ${ }^{6}$ Esto dio pie a una larga tradición en la región donde el poder central o federal era constantemente retado por poderes fácticos regionales.

Por esto, Edward Shils ha detallado cómo gran parte de los Estados en el Tercer Mundo fracasaron en consolidar su "centro", es decir, el escalafón supremo, encargado de dirigir los esfuerzos de consolidación del Gobierno. ${ }^{7}$ Estos fracasos en el Tercer Mundo generaron, por tanto, dicotomías entre lo que se dice en el centro del Estado y lo que se hace en la periferia. El Estado no logra consolidar una dominación territorial completa. Cede frecuentemente a grupos fácticos o sociales que tratan, a su vez, de establecer sus propias reglas del juego (uno de los argumentos centrales, asimismo, de la obra de Joel Migdal sobre el Tercer Mundo). ${ }^{8}$ En América Latina, Oszlak y O'Donnelll retrataron esta misma deficiencia estatal mediante la caracterización de las "distorsiones" de las políticas estatales: es decir, políticas "que [se] van desnaturalizando [en] su esencia a medida que nos alejamos del nivel de 'formulación de políticas' y nos acercamos al de materialización".9

A mediados del siglo xx, el desafío de los Estados latinoamericanos y el objetivo de sus respectivas políticas estatales era sacar a sus países de las circunstancias adversas que la Gran Depresión y la Segunda Guerra Mundial habían causado a nivel internacional. En apariencia, los Estados de la región lograron consolidar la estabilidad y centralización a base de regímenes autoritarios. El análisis de 0’Donnell y su concepción del "estado burocrático-autoritario”, sin embargo, pronto revelaría las tradicionales (y subyacentes) deficiencias de los gobiernos latinoamericanos.

A mediados del siglo pasado, algunas economías de América Latina -como México, Brasil, Chile, Uruguay y Argentina- experimentaron un impulso acelerado en el desarrollo de sus economías a través de la industrialización mediante sustitución de importaciones (III). ${ }^{10}$ A la par de este desarrollo industrial sin precedentes, dichos países de América Latina parecían gozar de una considerable

\footnotetext{
${ }^{6}$ Wiarda, Howard y Kline, Harvey, Latin American politics and development, Estados Unidos, Westview Press, 2013, p. 63.

${ }^{7}$ Respecto al "Estado en la sociedad", véase las contribuciones de Edward Shils dentro de la obra de MigdAL, JoE, State in Society: studying how states and societies transform and constitute one another, Estados Unidos, Cambridge University Press, 2001.

${ }^{8}$ Migdal, JoEL, State in society: studying how states and societies transform and constitute one another, Estados Unidos, Cambridge University Press, 2001.

${ }^{9}$ Oszlak, Oscar y O'Donnell, Guillermo, Estado y políticas estatales en América Latina: hacia una estrategia de investigación, Buenos Aires, Clacso, 1981.

${ }_{10}$ Panizza, Francisco, Contemporary Latin America: development and democracy beyond the Washington consensus, Londres, Zed Books, 2009.
} 
centralización y orden político. En el caso de México, por ejemplo, Samuel Huntington elogiaba a la Revolución mexicana como altamente exitosa, considerando su capacidad de establecer un orden institucional y flexible, que eventualmente mantendría al PRI al frente del Gobierno nacional durante siete décadas. ${ }^{11}$

En otros casos latinoamericanos, de igual forma, los Estados habían sido capaces de consolidar, aparentemente, grados substanciales de centralización y estabilidad mediante la presencia de las fuerzas armadas o los llamados Gobiernos pretorianos. Durante las décadas de 1950 a 1970, estos gobiernos autoritarios recurrieron al desarrollismo y a la ISI como una solución a las crisis económicas que le siguieron a la Segunda Guerra Mundial. Ello generó expansiones económicas sobresalientes; el sector automotriz es uno de los principales ejemplos. ${ }^{12}$ La obra de 0’Donnell fue entonces la primera en postular un enlace sistémico y teorético entre los regímenes autoritarios-burocráticos de América Latina y la industrialización de la región. ${ }^{13}$ Tal vez con mayor importancia, O'Donnell fue el primero en detectar las fracturas disfrazadas por los regímenes autoritarios de la región.

En palabras de O’Donnell, las apariencias "monolíticas" e "imponentes" de estos Estados burocráticos autoritarios, bajo un análisis más riguroso, no eran más que meras "fachadas" que cubrían a Estados plagados de "contradicciones, dilemas y peligros - los cuales reflejan las dificultades extraordinarias de consolidar un sistema de dominación". ${ }^{14}$ Este primer esfuerzo por revelar las "contradicciones", "distorsiones" y fragmentaciones inherentes de los Estados latinoamericanos sería pronto secundado por otros académicos para desentrañar los frágiles soportes que estos regímenes tenían (la exclusión de las masas, oligopolios económicos, el uso de la fuerza y la creciente dependencia en la burocracia). ${ }^{15}$

Pronto, no obstante, las coyunturas tanto nacionales como internacionales contribuyeron al derrocamiento de los regímenes autoritarios a través de

\footnotetext{
${ }^{11}$ Huntington, Samuel, Orden político en las sociedades en cambio, México, Taurus, 1996, p. 283.

${ }^{12}$ Kaufman, Robert, "Industrial Change and Authoritarian Rule in Latin America: A Concrete Review of the Bureaucratic-Authoritarian Model", en David Collier (ed.), The New Authoritarianism in Latin America, Princeton, Princeton University Press, 1979, p. 207.

${ }^{13}$ Kaufman, Robert, "Industrial Change and Authoritarian Rule in Latin America: A Concrete Review of the Bureaucratic-Authoritarian Model", en David Collier (ed.), The New Authoritarianism in Latin America, Princeton, Princeton University Press, 1979, p. 246.

${ }^{14}$ O'Donnell, Guillermo, 1979. "Tensions in the bureaucratic-authoritarian state and the question of democracy", en David Collier (ed.), The New Authoritarianism in Latin America, Princeton, Princeton University Press, 1979, pp. 285-318.

${ }^{15}$ Coluer, David, "Overview of the Bureaucratic Authoritarian Model", en David Collier (ed.), The New Authoritarianism in Latin America, Princeton, Princeton University Press, 1979.
} 
América Latina. La imposibilidad de conducir de manera eficiente la transición a las fases más avanzadas de isı le quitó aquella legitimidad tecnocrática en la que dichos regímenes se habían apoyado para consolidarse. Asimismo, la caída del muro de Berlín y el consecuente ascenso del neoliberalismo, de la mano de Reagan, Thatcher y organismos financieros internacionales, posicionaron la democratización y la descentralización como un necesario emparejamiento del capitalismo o economías de mercado.

Estos dos factores llevaron eventualmente a esa "tercera ola de democratización” protagonizada en gran medida por América Latina. ${ }^{16}$ Las transiciones de regímenes autoritarios a sistemas democráticos, sin embargo, no serían tarea fácil para los gobiernos de la región. Eventualmente, las desigualdades, crisis y cualidades fragmentadas del vínculo entre Estado y sociedad de los gobiernos autoritarios seguirían propagándose en las nuevas democracias o "poliarquías". ${ }^{17}$

\section{La crisis de Estado en AmÉrica latina a finales del siglo XX: DE DEMOCRACIAS EN TRANSICIÓN A DEMOCRACIAS EN DELEGACIÓN}

A partir de 1980, el ojo crítico de 0’Donnell se posó sobre la transición democrática que estaban viviendo países tanto en Europa como en el espacio postsoviético y en América Latina. ${ }^{18}$ En la región de América Latina, el desafío de resarcir los impactos negativos del legado del Estado Burocrático-Autoritario (EBA) se posicionó particularmente en dos frentes: el primero, en las instituciones políticas; el segundo, en el desarrollo económico o contexto socioeconómico de los países. Desafortunadamente, para la mayoría de los países de América Latina, la correlación positiva que en Europa occidental tuvieron las instituciones democráticas con el desarrollo económico no se cristalizó, lo cual dio pie a lo que Leftwich denominó "incompatibilidad institucional". 19

El teórico del desarrollo Adrian Leftwich, sin embargo, llegaría a dichas conclusiones ya en el siglo xxI. La difícil tarea que estudiosos de América Latina como el propio 0’Donnell tenían para la década de 1980 y 1990 era sondear

\footnotetext{
${ }^{16}$ Huntington, Samuel, The third wave: Democratization in the late twentieth century, vol. 4, Oklahoma, University of Oklahoma Press, 1993.

${ }_{17}$ O'Donnell, Guillermo, Polyarchies and the (Un)Rule of law in Latin America, Estados Unidos, LASA, 1998.

${ }^{18}$ O'Donnell, Guillermo \& Schmitter, Phillipe, Transitions from authoritarian rule: Tentative conclusions about uncertain democracies, Estados Unidos, John Hopkins University Press, 2013.

${ }^{19}$ Leftwich, Adrian, "Democracy and development: Is there institutional incompatibility?" Democratisation, vol. 12, núm. 5.
} 
los progresos (y retrocesos) de los gobiernos en transición de manera casi simultánea. Esta ambigua relación que se presentó entre desarrollo económico y democracia en la región durante esa "tercera ola democratizadora" llevó a 0'Donnell a caracterizar una nueva especie de democracia: la democracia delegativa. ${ }^{20}$ La democracia delegativa (DD) se basó en la premisa o "mito" de que el presidente se sumergía en un aislamiento institucional (de los demás poderes o grupos de interés) para asumir "en forma exclusiva la responsabilidad por los éxitos y fracasos de “sus' políticas”. ${ }^{21}$

La autoridad plena para definir el rumbo del país, en consecuencia, le era "delegada" al presidente electo por los ciudadanos votantes, que después se convertían en una audiencia halagüeña (al principio) o crítica (al final de su administración). Con esto, entonces, la obra de O’Donnell permitió detectar cierta migración de atributos de un tipo de gobierno (EBA) a otro (DD). Aparte de que el jefe de Gobierno seguía como anfitrión de poderes metaconstitucionales, otros dos elementos se terminaron traspasando del EBA a las DD de la región: primero, la política económica como eje definitorio y aliciente de la exacerbación del poder ejecutivo sobre otros poderes (que se convertían en meros obstáculos), y, segundo, el respaldo burocrático de dichas políticas económicas mediante el encumbramiento de la figura de los "técnicos" o "tecnócratas". 22

Ahora bien, la principal distinción entre los Estados burocráticos autoritarios y las posteriores democracias delegativas es la política económica legitimadora del autoritarismo o de la delegación, respectivamente. En el caso de los Estados burocráticos autoritarios, la política económica legitimadora fue el estructuralismo económico, originado en la hipótesis Prebisch-Singer, reflejado, a su vez, en la industrialización mediante la sustitución de importaciones. ${ }^{23}$ En contraste, la política económica que dio sustento a la mayoría de las democracias delegativas en América Latina fueron los llamados programas de ajuste estructural (SAP, por sus siglas en inglés) promovidos por el neoliberalismo de Reagan, Thatcher, el Fondo Monetario Internacional y el Banco Mundial. ${ }^{24}$ Estas medidas o paquetes neoliberales fueron

\footnotetext{
20 O'Donnel, Guillermo, "Delegative Democracy", Journal of Democracy, vol. 5, núm. 1, pp. 55-69.

${ }^{21}$ O'Donnell, Guillermo, "Delegative Democracy", Journal of Democracy, vol. 5, núm. 1, p. 61.

${ }^{22}$ O'Donnell, Guillermo, "Delegative Democracy", Journal of Democracy, vol. 5, núm. 1, p. 60.

${ }^{23}$ HIRSCHMAN, Albert, "The political economy of import-substituting industrialization in Latin America", The Quarterly Journal of Economics, vol. 82, núm. 1, pp. 1-32.

${ }^{24}$ Panizza, Francisco, Contemporary Latin America: development and democracy beyond the Washington consensus, Londres, Zed Books, 2009; véase también O'Donnell, Guillermo, "Estado, democratización y ciudadanía", Revista Nueva Sociedad, núm. 128, p. 14, sobre el "antiestatismo" de las políticas neoliberales.
} 
implementados en la Argentina de Alfonsín mediante el Plan Austral, en el Perú de García mediante el Plan Inti y en el Brasil de Sarney mediante el Plan Cruzado. ${ }^{25}$

Los programas de ajuste, sin embargo, lejos de traer milagros industriales —como los vistos en América Latina desde 1940 a 1970 aproximadamente-, generaron décadas de estancamiento económico, hiperinflación o crisis financieras como la del tequila de $1994 .{ }^{26}$ De paso, se expandieron las desigualdades sociales y regionales de los países latinoamericanos. Pronto, la demeritación de las políticas neoliberales en la región contribuyó a una reemergencia de las democracias delegativas, aunque con tintes nacionalistas: la Argentina de Kirchner, el Ecuador de Correa, García de nuevo en Perú y Chávez, y posteriormente Maduro, en Venezuela. ${ }^{27}$ Esto fue lo que Panizza concibió como "ola rosa" en la región. ${ }^{28}$ Esta remergencia de las democracias delegativas, a su vez, pasó por un ciclo similar de contento y descontento. En estas últimas fases, las deficiencias democráticas se agravan, generando discursos polarizadores y de amedrentamiento en detrimento de las cualidades participativas, plurales e inclusivas de una democracia. ${ }^{29}$

No obstante, ya sea mediante excesos o ausencias estatistas, las desigualdades regionales prevalecieron en la región. Al mismo tiempo, el proceso globalizador o glocalizador aumentó los protagonismos de plataformas subnacionales, tanto de gobierno como de comunidades, dando pie al siguiente reto gubernamental de los Estados de América Latina.

\section{GobernANZA MULTINIVEL Y PODER INFRAESTRUCTURAL: ¿REMEDIO PARA EL ESQUIZOFRÉNICO ESTADO LATINOAMERICANO?}

Tras el fracaso rotundo del Consenso de Washington en América Latina, ¿cuál era el siguiente paso para sus gobiernos? Aparentemente, lo que se necesitaba ahora para los gobiernos de América Latina era una evaluación funcional de las capacidades gubernamentales. Así, para apoyar a esas democracias embrionarias en su consolidación, surgió el ejercicio cartográfico de Guillermo O'Donnell respecto a las capacidades estatales, donde introduce un mapeo de

\footnotetext{
${ }^{25}$ O'Donnell, Guillermo, "Delegative Democracy", Journal of Democracy, vol. 5, núm. 1, pp. 63-64.

${ }^{26}$ MISHKIN, Frederic, "Lessons from the tequila crisis", Journal of Banking \&t Finance vol. 23, núm. 10.

${ }^{27}$ O'Donnell, Guillermo, "Revisando la democracia delegativa", Casa del tiempo, núm. 31.

${ }^{28}$ Panizza, Francisco, Contemporary Latin America: development and democracy beyond the Washington consensus, Londres, Zed Books, 2009.

${ }^{29}$ O'Donnell, Guillermo, "Revisando la democracia delegativa", Casa del tiempo, núm. 31, p. 8.
} 
ellas.

Imaginemos un mapa de cada país en el que las áreas cubiertas de azul designarian a aquéllas que tienen un alto grado de presencia del estado (en términos de contar con burocracias y marcos legales relativamente eficientes), tanto funcional como territorialmente; el color verde indicaría un alto grado de penetración territorial pero una presencia significativamente menor en términos de funcionalidad/clase; y el color café un nivel bastante bajo en ambas dimensiones. ${ }^{30}$

En ese entonces, O’Donnell procedería a clasificar a Noruega como un país cubierto completamente en azul; Estados Unidos en azul y verde, con algunos puntos cafés en el sur; y Brasil y Perú cubiertos casi totalmente por áreas cafés. Lo alarmante de este ejercicio es el hecho de que, en términos generales, la región de América Latina pudiera seguir, ya en el siglo XxI, bajo ese mismo color café, donde existen meramente "elecciones, gobernadores y legislaturas nacionales"; ${ }^{31} \mathrm{o}$, incluso, que se haya presenciado un retroceso de los derechos de sus ciudadanías (como lo ha expuesto O’Donnell para el caso de Chile, al igual que Louise Haagh). ${ }^{32}$

Los programas de ajuste estructural y el Consenso de Washington, influidos de igual forma por los postulados de la nueva gestión pública (o New Public Management), promovieron simultáneamente una minimización del Estado y una descentralización de funciones con base en criterios de eficiencia y rendición de cuentas. El problema fue que en la mayoría de los Estados latinoamericanos, los gobiernos carecían de los grados de gobernabilidad necesaria para lograr un desarrollo político y socioeconómico de manera integrada. $^{33}$

En consecuencia, la debilidad institucional de los gobiernos en América Latina, emparejada con la ola descentralizadora, terminó por incrementar las desigualdades subnacionales. Es decir, uno de los principales efectos adversos de la ola descentralizadora en estos Estados tradicionalmente fragmentados contribuyó a una mayor irregularidad o "esquizofrenia” gubernamental

\footnotetext{
${ }^{30}$ O'Donnell, Guillermo, "Estado, democratización y ciudadanía", Revista Nueva Sociedad, núm. 128, p. 11.

${ }^{31}$ O'Donnell, Guillermo, "Estado, democratización y ciudadanía", Revista Nueva Sociedad, núm. 128, p. 11.

32 O'Donnell, Guilermo, Democracia, agencia y estado: Teoría con intención comparativa, Buenos Aires, Prometeo, 2010; HAAGH, LouISE, Citizenship, labour markets and democratization: Chile and the modern sequence, Nueva York, Springer, 2002.

${ }^{33}$ Huntington, Samuel, Orden Politico en las Sociedades en Cambio, México, Taurus, 1996.
} 
proyectada en las diferencias entre Norte y Sur. ${ }^{34}$ Por esto mismo, O'Donnell se abocó a la elaboración de una "cartografía" de las contrastantes capacidades gubernamentales de los Estados latinoamericanos dentro de sus propias fronteras. La difícil tarea de homogeneizar las capacidades estatales de norte a sur sólo se ha exacerbado con el creciente impacto de la globalización (ya sea en sus vertientes políticas, económicas o sociales).

La globalización, desde finales del siglo pasado, postuló nuevos retos al Estado moderno en cuestión de soberanía, al verse forzado a compatibilizar prerrogativas supranacionales con prioridades nacionales del desarrollo (es decir, el dilema actual de la gobernanza multinivel). En América Latina, las tendencias hacia una gobernanza multinivel se profundizaron hacia el interior de cada país, puesto que la principal difusión de poder político se direccionó hacia plataformas subnacionales tras la ola descentralizadora de la década de 1990.

En el caso particular de América Latina, O’Donnell señaló tres crisis estaduales. ${ }^{35}$ En primera cuenta, un Estado de derecho (o legalidad) ineficiente, donde el acceso a la justicia se ve mermado por las desigualdades subyacentes en la población y por una rampante impunidad a lo largo de la región. En segundo lugar, se encuentra la crisis burocrática de los Estados latinoamericanos, como agentes fallidos de políticas públicas, que, a su vez, se relaciona con la crisis de legitimación del propio Estado.

Es en estas dos últimas crisis donde 0'Donnell hace referencia al impacto globalizador agudizado por políticas neoliberales y antiestatistas arraigadas en la región desde la década de $1980 .{ }^{36}$ Dichas políticas se fueron consolidando en la región en contra de las intervenciones estatales en temas de desarrollo económico y desarrollo social. Entre ellas, resaltan las medidas laborales que se propagaron en la región para impactar la competitividad de los salarios y, eventualmente, en la ciudadanía social.

Así entonces, en los últimos treinta años el salario mínimo en México ha perdido cerca de $77 \%$ de su poder adquisitivo. ${ }^{37}$ En el resto de América Latina, esta tendencia se agudizó durante 1980 y la primera mitad de 1990, cuando la inequidad de ingresos se multiplicó. ${ }^{38}$ Gran parte de esta inequidad, medida por el coeficiente Gini, se sigue propagando en la región debido

\footnotetext{
34 O'Donnell, Guillermo, "Estado, democratización y ciudadanía", Revista Nueva Sociedad, núm. 128, p. 7.

${ }^{35}$ O'Donnell, Guillermo, "Estado, democratización y ciudadanía", Revista Nueva Sociedad, núm. 128.

${ }^{36}$ O'Donnell, Guillermo, "Estado, democratización y ciudadanía", Revista Nueva Sociedad, núm. 128, p. 14.

${ }^{37}$ Esouivel, Gerardo, "Desigualdad extrema en México: concentración del poder económico y político", Reporte de Oxfam México, núm. 23, 2015.

${ }^{38}$ Gasparini Leonardo y Lustig, Nora, "Rise and Fall of Income Inequality in Latin America", Cedlas, 2011.
} 
a la ausencia de mecanismos redistributivos. Como lo demuestran comparativas entre América Latina y Europa, los mecanismos redistributivos de política fiscal impactan de manera importante en la disminución de la inequidad en Europa, mientras que en América Latina, de manera contrastante, las políticas fiscales tienen un impacto casi nulo en redistribuir la riqueza. ${ }^{39}$

Además, en América Latina la descentralización ha seguido agudizando los retos que el Estado enfrenta, de acuerdo con las distintas "extensiones y horizontes espaciotemporales de acción”. ${ }^{40}$ Dichas conceptualizaciones nuevas de los retos de consolidación territorial del Estado hacen eco con la heterogeneidad/homogeneidad de las capacidades funcionales del Estado que 0'Donnell postuló. "No se plantea (y si se hace raras veces se discute) si ese orden," escribe 0'Donnell, "y las órdenes emitidas por los organismos estatales tienen la misma eficacia a lo largo de todo el territorio nacional y a través de todos los estratos sociales existentes". ${ }^{41}$

Esta es la vertiente entonces que las calidades de gobierno, las "dimensiones espaciotemporales" o la "gobernanza multinivel" han retomado para avanzar en el análisis de una gobernabilidad democrática: la transición de una mera democracia electoral a una democracia ciudadana. Las capacidades funcionales y territoriales del Estado se han comenzado a analizar con mayor frecuencia en un intento por remediar precisamente esas cualidades esquizofrénicas del Estado. Más aún dentro de contextos posfuncionales de la organización de los Estados. ${ }^{42}$

Para el académico argentino, siguiendo los postulados de autores como Held y Evans, la globalización sí ha implicado nuevos retos para el Estado, aunque sin representar en automático un juego de suma-cero. Al contrario:

Los Estados del noroeste no han disminuido sus actividades frente a la globalización sino que respecto de algunas las han expandido y en otras han reacomodado sus instituciones (y las capacidades técnicas del caso) para regular y redireccionar la globalización hacia el bien público de sus poblaciones. ${ }^{43}$

\footnotetext{
${ }^{39}$ Véase GoÑı, Edwin, López, Humberto y Serven, Luis, Fiscal Redistribution and Income Inequality in Latin America, Banco Mundial, 2008.

${ }^{40}$ Jessop, BoB, The State: Past, Present, and Future, Cambridge, Polity Press, 2015

${ }^{41}$ O'Donnell, Guillermo, "Estado, democratización y ciudadania", Revista Nueva Sociedad, núm. 128, p. 7.

${ }^{42}$ Hooghe, Liesbet \& Marks, Gary, "A postfunctionalist theory of European integration: From permissive consensus to constraining dissensus", British Journal of Political Science, vol. 39, núm. 1.

${ }^{43}$ O'Donnell, Guilermo, "Hacia un Estado de y para la Democracia", en Rodolfo Mariani (coord.), Democracia/Estado/ Ciudadania: Hacia un Estado de y para la Democracia en América Latina, Estados Unidos, PNUd, 2007, p. 40. El "cuadrante Noroeste" de O'Donnell consta de Estados Unidos y el norte de Europa.
} 
Por esto mismo 0'Donnell rescata las formulaciones del académico Michael Mann entre el poder unilateral -un poder de decisión impositivo y centralizado- y el poder infraestructural -aquél que exhibe un poder estatal flexible e inclusivo, con capacidad de penetración a través de la sociedad, y no por encima de ella-. ${ }^{44}$ Esta penetración coordinada e inclusiva del Estado en sus distintos niveles es la habilidad que las nuevas exigencias globalizadoras exigen al Estado contemporáneo y que la mayoría de los Estados latinoamericanos no han podido superar.

Con estas perspectivas, no obstante, se ha revigorizado el estudio de las capacidades del Estado en América Latina, para analizar así las desiguales capacidades impositivas en las distintas plataformas subnacionales ${ }^{45}$ los variados protagonismos subnacionales en torno al desarrollo económico $;^{46}$ o los efectos que la globalización económica tiene en las distintas regiones o provincias de un mismo Estado.$^{47}$ Harbers incluso replica el ejercicio cartográfico de 0'Donnell para "mapear" las desiguales capacidades impositivas de Ecuador a nivel subnacional y puntualizar las diferentes capacidades funcionales del Estado según la localidad. ${ }^{48}$

La tarea pendiente de los países de América Latina es, por tanto, consolidar sistemas políticos con altos grados de gobernabilidad democrática y poder infraestructural. Gran parte de estas dificultades se deben a la heterogeneidad de los países, no sólo en cuanto a sus territorios sino en cuanto a sus sociedades o grupos étnicos. Consciente de las deficiencias que los Estados de la región venían arrastrando desde las últimas décadas, el académico argentino se cuestionó, ya en las últimas fases de su producción académica, cómo conformar democracias ciudadanas e incluyentes. ¿Cómo hacer de la gobernabilidad democrática una plataforma inclusiva de los heterogéneos grupos o estratos en América Latina?

\section{EnTRE AGENCIAS (DEMOCRÁtICAS) y ESTRUCTURAS (NO DEMOCRÁtICAS): INCREMENTANDO LA INTENSIDAD DE LAS CIUDADANÍAS}

\footnotetext{
${ }^{44}$ O'Donnell, Guillermo, "Hacia un Estado de y para la Democracia", en Rodolfo Mariani (coord.), Democracia/Estado/ Ciudadanía: Hacia un Estado de y para la Democracia en América Latina, Estados Unidos, PNUd, 2007, p. 47. En dicha referencia se detalla esta clasificación de poderes según Michael Mann en su libro The Sources of Social Power.

${ }^{45}$ HARBERS, IMKE, "Taxation and the unequal reach of the state: Mapping state capacity in Ecuador", Governance, vol. 28, núm. 3 .

${ }^{46}$ Wilson, Robert, Ward, Peter, Spink, Peter \& Rodriguez, Victoria, Governance in the Americas: Decentralization, Democracy, and Subnational Government in Brazil, Mexico and the USA, Indiana, Notre Dame Press, 2008.

${ }^{47}$ LI, Quan y Reuveny, Rafael, "Economic Globalization and Democracy: An Empirical Analysis", British Journal of Political Science, 2003.

${ }^{48}$ HARBERS, IMKE, "Taxation and the unequal reach of the state: Mapping state capacity in Ecuador", Governance, vol. 28 , núm. 3.
} 
Ante las crecientes desigualdades en el mundo, donde el hueco entre clases acomodadas y clases pobres sigue ampliándose, la ciudadanía ha desconfiado ya de los actuales mecanismos de representación. El ejemplo de Brexit no es sólo una cerrazón ante la Unión Europea debido a fobias migratorias, es también un esfuerzo de la ciudadanía por aclarar en mayor medida las reglas de rendición de cuentas en relación a sus gobernantes. En el nuevo siglo, la interrogante no es sólo el tipo de gobierno para nuestros países, sino el grado de gobierno, como lo postuló Samuel Huntington. ${ }^{49}$ En torno a la democracia, el foco de análisis parece ser el mismo: no el tipo de democracia (parlamentaria, presidencial o mixta), sino el grado de la democracia.

Es aquí donde entra el principal reto de las democracias contemporáneas: la inclusión de las distintas ciudadanías o, en palabras de 0'Donnell, la remediación de las "ciudadanías de baja intensidad"..$^{50}$ ¿Cómo transitar entonces de ciudadanías de baja intensidad a ciudadanías de alta intensidad? ¿De meras democracias electorales a democracias ciudadanas? De inicio, al menos, los grados democráticos pudieran dividirse en dos: un grado mínimo, caracterizado por meras democracias electorales, y un grado máximo, compuesto por democracias ciudadanas u holísticas.

Conforme con indicadores del Programa de Desarrollo de las Naciones Unidas, la democracia electoral contempla el reconocimiento del derecho universal al voto y a las elecciones como el "medio de acceso a cargos públicos" ${ }^{51}$ La democracia ciudadana, en cambio, es aquella que contempla la aplicación de los derechos ciudadanos en sus tres principales espectros —desde los políticos (contemplados generalmente por la democracia electoral), hasta los civiles y sociales-. Es en estos dos últimos derechos (civiles y sociales) donde las democracias latinoamericanas se quedan sustancialmente cortas.

La democracia, sí, debiera ser un ideal constante tal cual lo consideró Sartori $;^{52}$ pero lo más importante es que nuestras democracias se conviertan en un modus vivendi u operandi (un marco gubernamental no sólo para elegir a nuestros gobernantes, sino para vivir en condiciones de equidad y justicia). El reconocimiento de las insuficiencias de una democracia electoral pudiera entonces asimilarse con la dicotomía hecha por Norberto Bobbio entre Estados mínimos y Estados sociales. ${ }^{53}$ Siguiendo los postulados de Bobbio, los

\footnotetext{
${ }^{49}$ Huntington, Samuel, Orden politico en las sociedades en cambio, México, Taurus, 1996.

${ }^{50}$ O'Donnell, Guillermo, "Estado, democratización y ciudadanía", Revista Nueva Sociedad, núm. 128.

${ }^{51}$ PNUD, La democracia en América Latina: Hacia una democracia de ciudadanas y ciudadanos, 2004, Perú, PNUD, p. 27.

52 PNUD, La democracia en América Latina: Hacia una democracia de ciudadanas y ciudadanos, Perú, PNUD, 2004.

${ }^{53}$ Bobbio, Norberto, El futuro de la democracia, México, Fondo de Cultura Económica, 2005.
} 
Gobiernos democráticos ahora deben reconfigurar su concepción moderna de mera democracia representativa o electoral a una democracia ciudadana.

A lo largo de su existencia, a la democracia representativa se le ha hecho "inherente la desvinculación del representante de la nación del individuo representado y de sus intereses particulares". ${ }^{54}$ Lo que ahora debiera exigirse a nuestras democracias es precisamente lo contrario: vincular los intereses de bienestar y desarrollo de los ciudadanos a las directrices nacionales de los Estados.

En palabras de Malloch Brown, "la mejor manera de conseguirlo de forma coherente con los objetivos del desarrollo humano es erigir formas firmes y profundas de gobernabilidad democrática en todos los niveles de la sociedad" ${ }^{55}$ En esta línea, Guillermo 0’Donnell rescató a quien debiera ser el agente detonador de las instituciones democráticas en un país: el ciudadano. Para que se dé un círculo virtuoso entre las dicotomías de agencias (de impulso democrático) y estructuras (con deficiencias democráticas), las ciudadanías deben contemplar, en todos los estratos y grupos, los tres niveles de derechos: no sólo políticos, sino sociales y civiles también mediante la vinculación del elemento micro de la democracia (el ciudadano como agente subjetivo de derechos) con el elemento macro (Estado)..$^{56}$ Por esto mismo es por lo que surge la clarificación de que la democracia "incluye un régimen político pero no se agota en él" y que, de igual forma, una democracia plena "implica la extendida existencia de otras ciudadanías: civil, social y cultural". ${ }^{57}$

Ese en este punto donde el académico argentino clarifica el panorama de las deficientes democracias en América Latina, en contraste con los países de lo que caracteriza como "cuadrante noroeste" que incluye al norte de Europa y Estados Unidos: la prevalente incapacidad de mejorar las atribuciones estatales en América Latina aunada a la ausencia distributiva del bienestar en la región. ${ }^{58}$

Bajo similares líneas, O’Donnell resaltó la secuencia de derechos de Marshall en relación con América Latina, donde sólo las democracias más

\footnotetext{
${ }^{54}$ Bobвio, Norberto, Liberalismo y democracia, México, Fondo de Cultura Económica, 2010, p. 38

${ }^{55}$ PNUD, La democracia en América Latina: Hacia una democracia de ciudadanas y ciudadanos, Perú, PNUD, 2004, p. 30.

${ }^{56}$ O'Donnell, Guillermo, Democracia, agencia y estado: teoría con intención comparativa, Buenos Aires, Prometeo, 2010. Véase también O'Donnell, GulleERmo, "Democracy, Law, and Comparative Politics", Studies in Comparative International Development, 2001, desde donde inicia a concebir su perspectiva de "agencia" en Estados democráticos. ${ }^{57}$ O'Donnell, Guillermo, "Hacia un Estado de y para la Democracia", en Rodolfo Mariani (coord.), Democracia/Estado/ Ciudadanía: Hacia un Estado de y para la Democracia en América Latina, Estados Unidos, PNUD, 2007, p. 26.

${ }_{58}$ O'Donnell, Guillermo, Democracia, agencia y estado: teoría con intención comparativa, Buenos Aires, Prometeo, 2010.
} 
consolidadas (Uruguay, Chile y Costa Rica) asimilaron esa secuencia de derechos de Europa occidental: la adquisición de derechos civiles, luego los derechos políticos mediante la implementación de los sufragios y, por último, la adquisición de derechos sociales para las ciudadanías, principalmente con las políticas públicas de los Estados de bienestar (welfare States). En el resto de América Latina, por otro lado, se conformó lo que O’Donnell caracterizó como secuencia populista: primero la asimilación de derechos sociales, aunque con considerables rezagos en las últimas dos décadas, luego la adquisición de derechos políticos y, finalmente, la de derechos civiles, aunque estos últimos en forma intermitente y con sesgos políticos o sociales importantes. ${ }^{59}$

Dichos sesgos, en consecuencia, han agravado las desigualdades sociales del país como uno de los efectos negativos del "particularismo" de las instituciones políticas de la región, donde criterios parroquiales o personalistas siguen soslayando el universalismo normativo que viene implícito con la función pública. ${ }^{60}$ Es decir, el problema con las instituciones políticas de América Latina no es una falta de consolidación; sino que las instituciones que se han consolidado en la región, principalmente las informales, han seguido ese mismo patrón personalista que agrava las desigualdades sociales. ${ }^{61}$

Esto motivó entonces al académico argentino, en sus últimas producciones científicas, a buscar las bases para la construcción de "un Estado de y para la democracia en América Latina". ${ }^{2}$ Para demarcar la ruta de acción en cuanto a esta necesaria construcción de los Estados en la región, resalta cuatro dimensiones o funciones básicas del Estado: eficacia de su burocracia; efectividad de su Estado de derecho o sistema legal; proyección del propio Estado como foco de identidad de su población; y, por último, el nivel de bienestar impulsado por filtros estatales. ${ }^{63}$

\footnotetext{
${ }^{59}$ Véase O'Donnell, Guillermo, "Institutionalization of agency", en Guillermo O'Donnell, Cullel \& lazzetta (eds.), The Quality of Democracy: Theory and Applications, Indiana, Notre Dame Press, 2004.

${ }^{60}$ O'Donnell, Guillermo, "llusiones sobre la consolidación", Nueva Sociedad, núm. 144.

${ }^{61}$ O'Donnell, Guilermo, "Ilusiones sobre la consolidación", Nueva Sociedad, núm. 144; véase también O'Donnell, GuiLLERMo, "Algunas reflexiones acerca de la democracia, el Estado y sus múltiples caras", Revista del CLAD Reforma y Democracia, núm. 42, donde detalla la forma sesgada en que las distintas "caras" del Estado son proyectadas.

${ }^{62}$ O'Donnell, Guillermo, "Hacia un Estado de y para la Democracia", en Rodolfo Mariani (coord.), Democracia/Estado/ Ciudadania: Hacia un Estado de y para la Democracia en América Latina, Estados Unidos, PNUD, 2007.

${ }^{63}$ Conceptualizaciones formuladas en O'DonneLL, GuILERMo, Democracia, agencia y estado: teoría con intención comparativa, Buenos Aires, Prometeo, 2010; y en O'Donnell, Gullermo, "Hacia un Estado de y para la Democracia", en Rodolfo Mariani (coord.), Democracia/Estado/Ciudadanía: Hacia un Estado de y para la Democracia en América Latina, Estados Unidos, PNUD, 2007.
} 
Lo que prevalece hoy día en América Latina es un Estado que "no penetra ni controla el conjunto de su territorio, [que] ha implantado una legalidad frecuentemente truncada y [que] la legitimidad de la coerción que lo respalda es desafiada por su escasa credibilidad como intérprete y realizador del bien común”. ${ }^{64}$ Estas últimas contribuciones de 0’Donnell en torno a los Estados democráticos son entonces los que pudieran fungir como puente en las evolventes tareas de reconstrucción de los gobiernos latinoamericanos -con énfasis en las cartografias de gobernabilidad, en el poder infraestructural del Estado y en las cuatro dimensiones de este mismo-.

\section{Conclusión}

Desde los primeros intentos por sistematizar una teoría de los regímenes autoritarios en América Latina a mediados del siglo pasado hasta el elusivo proceso de sus continuas o incompletas transiciones democráticas, 0’Donnell postuló herramientas tanto conceptuales como analíticas para acompañar el desarrollo democrático de los Estados latinoamericanos.

En la literatura contemporánea, la obra de 0'Donnell sigue vigente como especie de instructivo o manual para seguir enfrentando los problemas tradicionales de esa sociedad en conflicto que es América Latina: la persistencia de la desigualdad, las cualidades esquizofrénicas del Estado, el endeble Estado de derecho y las dificultades que la descentralización ha multiplicado en cuestión de gobernanza multinivel.

El objetivo del presente artículo fue entonces mapear esa trayectoria que la obra de 0'Donnell ha representado desde mediados del siglo pasado para comprender el desarrollo político de América Latina y postular herramientas de análisis que contribuyan a consolidar sus democracias ante los retos contemporáneos. Ello al considerar, de inicio, que las transiciones de los países latinoamericanos de meras poliarquías a democracias ciudadanas con Estados de derecho democráticos están aún lejos de consolidarse.

\footnotetext{
${ }^{64}$ O'Donnell, Guillermo, Acerca del estado en América Latina contemporánea: diez tesis para discusión. La Democracia en América Latina, Bogotá, PNUd, 2004, p. 34.
} 


\section{Bibliografía}

Ansaldi, Waldo, La democracia en América Latina: ¿un barco a la deriva?, México, Fondo de Cultura Económica, 2007.

Bobbio, Norberto, El futuro de la democracia, México, Fondo de Cultura Económica, 2005.

Bobbio, Norberto, Liberalismo y democracia, México, Fondo de Cultura Económica, 2010.

COLlIER, DAvid, "Overview of the Bureaucratic Authoritarian Model”, en David Collier (ed.), The New Authoritarianism in Latin America, Princeton, Princeton University Press, 1979.

Esquivel, Gerardo, “Desigualdad extrema en México: concentración del poder económico y político”, Reporte de Oxfam México, núm. 23, 2015

Gasparini, LeOnardo y Lustig, Nora, "Rise and Fall of Income Inequality in Latin America”, Cedlas, 2011.

GoÑI, Edwin, LóPez, Humberto y Serven, Luis, Fiscal Redistribution and Income Inequality in Latin America, Banco Mundial, 2008.

HaAgh, Louise, Citizenship, labour markets and democratization: Chile and the modern sequence, Nueva York, Springer, 2002.

HARBERS, ImKe, "Taxation and the unequal reach of the state: Mapping state capacity in Ecuador", Governance, vol. 28, núm. 3.

Hirschman, Albert, "The political economy of import-substituting industrialization in Latin America”, The Quarterly Journal of Economics, vol. 82, núm. 1.

Hooghe, LIESBEt \& MARKs, GARY, “A postfunctionalist theory of European integration: From permissive consensus to constraining dissensus”, British Journal of Political Science, vol. 39, núm. 1.

Huntington, SAmuel, The third wave: Democratization in the late twentieth century, vol. 4, Oklahoma, University of Oklahoma press, 1993.

Huntington, Samuel, Orden politico en las sociedades en cambio, México, Taurus, 1996.

Jessop, Boв, The State: Past, Present, and Future, Cambridge, Polity Press, 2015.

Kaufman, Robert, "Industrial Change and Authoritarian Rule in Latin America: A Concrete Review of the Bureaucratic-Authoritarian Model", en David Collier (ed.), The New Authoritarianism in Latin America, Princeton, Princeton University Press, 1979.

LefTwich, Adrian, "Democracy and development: Is there institutional incompatibility?” Democratisation, vol. 12, núm. 5.

Li, Quan y Reuveny, Rafael, "Economic Globalization and Democracy: An Empirical Analysis", British Journal of Political Science, 2003.

Migdal, Joel, State in Society: studying how states and societies transform and constitute one another, Cambridge, Cambridge University Press, 2001. 
Mishrin, Frederic, "Lessons from the tequila crisis", Journal of Banking \&t Finance, vol. 23, núm. 10.

O'Donnell, Guillermo, “Tensions in the bureaucratic-authoritarian state and the question of democracy", en David Collier (ed.), The New Authoritarianism in Latin America, Princeton, Princeton University Press, 1979.

O’Donnell, Guillermo, “Estado, democratización y ciudadanía”, Revista Nueva Sociedad, núm. 128.

O’Donnell, Guillermo, “Delegative Democracy”, Journal of Democracy, vol. 5, núm. 1. O’Donnell, Guillermo, "Ilusiones sobre la consolidación”, Nueva Sociedad, vol. 144.

O'Donnell, Gullermo, Polyarchies and the (Un)Rule of Law in Latin America, Estados Unidos, LASA, 1998.

O’Donnell, Guillermo, "Democracy, Law, and Comparative Politics”, Studies in Comparative International Development, vol. 36, núm. 1.

O’Donnell, Guillermo, “Acerca del estado en América Latina contemporánea: diez tesis para discusión”, en La Democracia en América Latina. PNUD. Bogotá, DC, 2004.

O’Donnell, Guillermo, “Institutionalization of agency”, en Guillermo 0’Donnell, Cullel \& Iazzetta (eds.), The Quality of Democracy: Theory and Applications, Indiana, Notre Dame Press, 2004.

O’Donnell, Guillermo, "Hacia un Estado de y para la Democracia”, en Rodolfo Mariani (coord.), Democracia/Estado/Ciudadania: Hacia un Estado de y para la Democracia en América Latina, Estados Unidos, PNUD, 2007.

O’Donnell, Guillermo, “Algunas reflexiones acerca de la democracia, el Estado y sus múltiples caras”, Revista del CLAD Reforma y Democracia, vol. 42.

O’Donnell, Guillermo, Democracia, agencia y estado: Teoría con intención comparativa, Buenos Aires, Prometeo, 2010.

O’Donnell, Guillermo, "Revisando la democracia delegativa”, Casa del tiempo, vol. 31, 2010.

O’Donnell, Guillermo \& Schmitter, PhilipPe, Transitions from authoritarian rule: Tentative conclusions about uncertain democracies, Estados Unidos, John Hopkins University Press, 2013.

O’Gorman, Edmundo, La invención de América, México, Fondo de Cultura Económica, 1958.

Oszlak, Oscar y O’Donnell, GuILlermo, Estado y políticas estatales en América Latina: hacia una estrategia de investigación, Buenos Aires, Clacso, 1981.

Panizza, Francisco, Contemporary Latin America: development and democracy beyond the Washington consensus, Londres, Zed Books, 2009.

PNUD, La democracia en América Latina: Hacia una democracia de ciudadanas y ciudadanos, Perú, PNUD, 2004.

Tilly, Charles y Ardant, Gabriel, The Formation of National States in Western Europe, Nueva Jersey, Princeton University Press, 1975. 
Esquivel, Gerardo, "Desigualdad extrema en México: concentración del poder económico y político”, Reporte de Oxfam México, núm. 23.

Wiarda, HoWARD, The soul of Latin America: The cultural and political tradition, New Haven, Yale University Press, 2003.

Wiarda, Howard y Kuine, Harvey, Latin American politics and development, Boulder, Westview Press, 2013.

Wilson, Robert, Ward, Peter, Spink, Peter \& Rodríguez, Victoria, Governance in the Americas. Descentralization, Democracy, and Subnational Government in Brazil, Mexico, and the USA, Indiana, University of Notredame, 2008. 